\title{
Catalytic Reduction of Benzaldehyde under Hydrogen Flow over Nickel-Containing Mesoporous Silica Catalysts
}

\author{
Adel Saadi $^{1}$, Kahina Lanasri ${ }^{1}$, Khaldoun Bachari ${ }^{1,2}$, Djamila Halliche $^{1}$, Chérifa Rabia ${ }^{1}$ \\ ${ }^{1}$ Laboratoire de Chimie du Gaz Naturel, Faculty of Chemistry, University of Sciences and Technology Houari Boumediene, \\ Algiers, Algeria \\ ${ }^{2}$ Centre de Recherche Scientifique et Technique en Analyses Physico-Chimiques, Algiers, Algeria \\ Email: asaadi@usthb.dz
}

Received October 28, 2011; revised November 29, 2011; accepted December 29, 2011

\begin{abstract}
The hydrogenation of benzaldehyde over a series of nickel-containing mesoporous silicas with different nickel contents was studied at atmospheric pressure in the range temperature of $393-513 \mathrm{~K}$ under $\mathrm{H}_{2}$ flow. These materials (noted $\mathrm{Ni}_{n}$-HMS with $\mathrm{n}=\mathrm{Si} / \mathrm{Ni}=50,25,15$ ) have been prepared at room temperature using a route based on hydrogen bonding and self-assembly between neutral primary amine micelles $\left(\mathrm{S}^{0}\right)$ and neutral inorganic precursors $\left(\mathrm{I}^{0}\right)$. They were characterized by their chemical analysis, BET surface area, XRD, FT-IR, and SEM microscopy. The obtained products were benzylalcohol, toluene, benzene with yields depending on the nickel content ( $\mathrm{Si} / \mathrm{Ni}$ ratio) and reaction temperature. The products of benzaldehyde hydrogenation (benzylalcohol, and toluene) and hydrogenolysis (benzene) were preferentially formed at low/middle and high reaction temperature respectively. The mesoporous Ni-containing materials were very active hydrogenation catalysts with almost $90 \%$ selectivity to benzylalcohol product and showed excellent stability. A mechanism in which the reaction could be initiated by a benzaldehyde reduction over $\mathrm{Ni}_{\mathrm{n}}-\mathrm{HMS}$ materials under hydrogen flow with formation of reaction products is proposed.
\end{abstract}

Keywords: Nickel; HMS; Benzaldehyde; Reduction; Mesoporous Materials

\section{Introduction}

One class of reactions important to produce fine chemical compounds is the hydrogenation of aldehydes and ketones [1-5]. Benzaldehyde reduction is one of these reactions which can provide information about nature and properties of surface centers [6-11]. It was found that nickel, platinum and copper based catalysts preferentially hydrogenate the carbonyl group [12-15]. For the aromatic compounds, the benzene ring and the carbonyl group should be hydrogenated but hydrogenolysis should also compete $[9,14,16]$. The obtained selectivities mainly depended on the nature of the catalyst $[3,4,15]$.

Heterogeneous catalytic studies of benzaldehyde hydrogenation have been largely devoted to the liquid phase medium $[5,17,18]$ whereas few other studies have been reported for the gas phase medium $[7,12,19]$. The later system were studied over metal supported catalysts [6, $12,14]$ or metal oxides catalysts $[7,13]$ but no works have been reported using metal-containing hexagonal mesoporous silica as catalysts. For the metal supported catalysts it was suggested that the observed performances were related to new active sites created in the metalsupport interfacial region $[6,20]$ whereas for metal oxides catalysts it was found that they strongly depended on both the re- ducibility and surface acid-base properties [7,13]. We recently confirmed the role of metal and acid-base properties in the same reaction conducted over copper supported catalysts [10].

The substitution of supported catalysts or metal oxides catalysts in the case of the hydrogenation reactions is an important challenge that is in heterogeneous catalysis. Indeed, several solid catalysts have already been proposed which are efficient catalysts. The discovery of the new family of mesoporous silica molecular sieves with pore diameters in the $2.0-10 \mathrm{~nm}$ range, designated as M41S, is of considerable interest for heterogeneous catalysis and material science $[21,22]$. This family of materials is characterized by a regular array of pores with uniform diameter, high specific surface areas and pore volumes, which are advantageous for the adsorption and catalysis.

Depending on the synthesis conditions, and on the surfactant $/ \mathrm{SiO}_{2}$ ratio, different phases could be obtained, like the hexagonal phase MCM-41, the cubic one MCM48 , and the lamellar compound MCM-50 [21,22]. In 1994, a new pathway was proposed by Tanev et al. [23] to prepare mesoporous silicas at room temperature by a neutral templating route $\left(\mathrm{S}^{0} \mathrm{I}^{0}\right)$. In this case, the organic 
surfactant is not quaternary ammonium cation but a primary amine, and the assembly involves hydrogen-bonding interactions between neutral primary amines and neutral inorganic precursors. These materials denoted HMS (hexagonal mesoporous silica) exhibit excellent catalytic ability for macromolecular reactions and offer new opportunities for transition metal incorporation into silica frameworks [24-27].

In the present paper, we report the synthesis and characterization of such materials incorporating nickel and their test as catalysts for the hydrogenation of benzaldehyde. The correlations between the catalytic activity and the surface property, the nature of active sites and the reaction mechanism have been investigated.

\section{Experimental}

\subsection{Catalysts Preparation}

The Ni-hexagonal mesoporous solid (HMS) catalysts were prepared as described previously [23]. Hexadecylamine (HDA), nickel nitrate $\left(\mathrm{Ni}\left(\mathrm{NO}_{3}\right)_{3} \cdot 6 \mathrm{H}_{2} \mathrm{O}\right)$, and then tetraethylorthosilicate (TEOS) were added to water and ethanol (EtOH) solutions. The dissolution of each component was carried out until completion before the next one was added. After mixing, the resulting solutions with composition [29]:

$$
\mathrm{SiO}_{2}-(1 / 2)_{\mathrm{n}} \mathrm{NiO}-0.3 \mathrm{HDA}-7 \mathrm{EtOH}-35 \mathrm{H}_{2} \mathrm{O} \text {, }
$$

where $n=\mathrm{Si} / \mathrm{Ni}=50,25,15$, were stirred at room temperature for $24 \mathrm{~h}$.

The solids thus obtained were recovered by filtration, washed with distilled water, and air-dried at $393 \mathrm{~K}$. Organic molecules occluded in the mesopores were removed by dispersing the solid $(5 \mathrm{~g} / 100 \mathrm{ml})$ in a solution of ethanol containing $\mathrm{NH}_{4} \mathrm{Cl}(1 \mathrm{~g} / 100 \mathrm{ml})$ and maintained under vigorous stirring for $2 \mathrm{~h}$. The procedure was repeated twice before drying at $393 \mathrm{~K}$ and calcination at $823 \mathrm{~K}$ in air for $6 \mathrm{~h}$. The samples are referred to as $\mathrm{Ni}_{\mathrm{n}}-\mathrm{HMS}$, where $\mathrm{n}$ is the $\mathrm{Si} / \mathrm{Ni}$ ratio in the solutions.

\subsection{Characterization Methods}

The chemical compositions of the samples were determined by atomic absorption using Perkin-Elmer 2380 spectrophotometer. The surface area was calculated based on the BET (Brunner-Emmett-Teller) method, while pore size distribution was computed using the BJH (Bar-
rett-Joyner-Halenda) method. X-ray diffraction (XRD) patterns obtained using a Siemens D500 diffractometer and $\mathrm{CuK} \alpha$ radiation, were recorded with $0.02^{\circ}(2 \theta)$ steps and $1 \mathrm{~s}$ counting time per step between $1^{\circ}$ and $10^{\circ}(2 \theta)$ and between $10^{\circ}$ and $80^{\circ}(2 \theta)$. The FTIR spectroscopy analysis has been carried out on a Phillips 9800-FTIR spectroscopy type. The $\mathrm{Ni}_{\mathrm{n}}$-HMS catalysts have also been examined with a scanning electron microscope (SEM), a JEOL2000 electron microscope.

\section{Catalytic Testing}

The catalytic performances were carried out in a fixedbed glass tubular reactor at atmospheric pressure with 30 mg samples and the total flow rate of $50 \mathrm{~cm}^{3} \cdot \mathrm{min}^{-1}$. The reactant gas feed consisted of 4.8 torr of benzaldehyde (Aldrich, 99.98\%) and 250 torr of $\mathrm{H}_{2}$ diluted in $\mathrm{N}_{2}$. Gaseous benzaldehyde was obtained by bubbling $\mathrm{N}_{2}$ in liquid benzaldehyde maintained at constant temperature $(323 \mathrm{~K})$ in a suitable saturator. Before testing, the catalysts were in-situ reduced for $2 \mathrm{~h}$ at $623 \mathrm{~K}$ in flowing $\mathrm{H}_{2}$ (flow rate of $20 \mathrm{~cm}^{3} \cdot \mathrm{min}^{-1}$ ).

The gaseous reactant and products were heated upstream and outstream and analyzed on line by a FID gas chromatograph (Delsi IGC $121 \mathrm{ML}$ ) equipped with a $10 \%$ CP-SIL 8 CB/Chromosorb W column. Each reaction temperature was maintained constant until the corresponding steady-state was reached as indicated by the gas chromatograph analysis of the exit gases samples. For each catalyst, the reaction temperature was changed in a crossing order: $473 \mathrm{~K}, 393 \mathrm{~K}, 513 \mathrm{~K}, 433 \mathrm{~K}$. Using the Weisz modulus, varying sample weight and flow rate in the range of $10 \mathrm{~cm}^{3} \cdot \mathrm{min}^{-1}$ to $80 \mathrm{~cm}^{3} \cdot \mathrm{min}^{-1}$ results showed that no mass transfer limitations occurred when the sample weight was $\leq 30 \mathrm{mg}$.

\section{Results and Discussion}

\subsection{Chemical Composition and BET Surface Area}

The Si/Ni ratio of the compounds was varied over a very wide range (15 - 50) to characterize all of the nickel species that may be formed in this type of compound. The chemical composition of catalysts obtained by AAS shows that $\mathrm{Si} / \mathrm{Ni}$ ratios are relatively closer to those fixed before the preparation and correspond well to the nominal values (see Table 1). This result confirms that

Table 1. Chemical composition and the characteristics of $\mathrm{Ni}_{\mathbf{n}}-\mathrm{HMS}$ catalysts.

\begin{tabular}{|c|c|c|c|c|c|c|}
\hline \multirow{2}{*}{ Sample } & \multicolumn{2}{|c|}{ Chemical analysis } & \multirow{2}{*}{$\mathrm{S}_{\mathrm{BET}}\left(\mathrm{m}^{2} \cdot \mathrm{g}^{-1}\right)$} & \multirow{2}{*}{$\begin{array}{l}\text { Pore volume } \\
\left(\mathrm{cm}^{3} \cdot \mathrm{g}^{-1}\right)\end{array}$} & \multirow{2}{*}{ Pore Diameter $(\AA)^{\mathrm{a}}$} & \multirow{2}{*}{ Wall thickness $(\AA)^{\mathrm{a}}$} \\
\hline & Si/Ni (gel) & Si/Ni (AAS) & & & & \\
\hline HMS & - & - & 1120 & 0.97 & 38 & 38.0 \\
\hline $\mathrm{Ni}_{50}-\mathrm{HMS}$ & 50 & 48.5 & 1143 & 0.90 & 28 & 27.7 \\
\hline $\mathrm{Ni}_{25}-\mathrm{HMS}$ & 25 & 23.6 & 1035 & 0.88 & 27 & 26.3 \\
\hline $\mathrm{Ni}_{15}$-HMS & 15 & 14.4 & 998 & 0.82 & 24 & 24.1 \\
\hline
\end{tabular}

${ }^{\mathrm{a}} \mathrm{BJH}$ (Barrett, Joyner and Halenda); ${ }^{\mathrm{b}}$ Wall thickness = d-spacing (calcined sample)—pore diameter (BJH). 
practically all the metal introduced in preparation gel is located in the catalyst.

The textural analysis of calcinated solids shows that the HMS structure exhibits a high specific surface (1120 $\mathrm{m}^{2} \cdot \mathrm{g}^{-1}$ ) with pore diameter of about $38 \AA$. This result confirms the presence of wide pores due to the mesoporous structure of synthesized material (between 25 and 50 $\AA$ ). The BET surface areas and pore volumes of the $\mathrm{Ni}_{\mathrm{n}}$ HMS samples are in the range of $990-1150 \mathrm{~m}^{2} \cdot \mathrm{g}^{-1}$ and $0.8-0.9 \mathrm{~cm}^{3} \cdot \mathrm{g}^{-1}$ respectively (Table $\mathbf{1}$ ).

In the present case, the surface areas and pore volumes of the $\mathrm{Ni}_{\mathrm{n}}$-HMS samples are lower than the value of HMS material. Indeed, after incorporation of Ni element in the HMS structure, the results show that BET surface area and, consequently the pore volume, decreases with decreasing of $\mathrm{Si} / \mathrm{Ni}$ ratio.

\subsection{FTIR and XRD Results}

In order to investigate the binding interaction between $\mathrm{Ni}$ and the surface functional groups of HMS structure, the $\mathrm{Ni}_{\mathrm{n}}$-HMS samples were characterized by FT-IR spectra, and their IR spectra were shown in Figure 1.

Characteristic bands of the HMS structure have been observed at $3420 \mathrm{~cm}^{-1}$ for the silanol group $\mathrm{Si}-\mathrm{OH}$ (not presented), between 800 and $700 \mathrm{~cm}^{-1}$ for Si-O-Si, and the band near $960 \mathrm{~cm}^{-1}$ corresponding to Si-O-Ni. Although there are still some disputes $[20,21]$ to the assignment of the $960 \mathrm{~cm}^{-1}$ band, but more evidences, in which a similar band was previously observed in titanium siloxane polymers or in $\mathrm{TiO}_{2}$-grafted on silica [25], have supported that the $960 \mathrm{~cm}^{-1}$ should be due to a modification of $\mathrm{SiO}_{4}$ units directly related to the presence of a strong binding of the surface functional groups of
HMS with Nickel. On the other hand, the IR spectra show that the intensity of Ni-O-Si band increases with increasing nickel content.

The X-ray diffraction is one of the most used techniques to identify HMS structure. It also gives information about the internal structure of solid, the nature and purity of crystallized material. The Figure 2 shows that only one peak reflection (100) appeared in the range of $2 \theta=2^{\circ}-5^{\circ}$, which is corresponding to the well-ordered hexagonal mesoporous structure [30,31]. The intensity of this peak decreases with increasing nickel content, demonstrating that adding nickel has probably a negative effect on crystallinity.

At the same time, small peaks corresponding to $\mathrm{NiO}$ phase appeared in the $10^{\circ}-80^{\circ}(2 \theta)$ range and grew with the nickel content. Figure 3 showed that, when the nickel content increased from $\mathrm{n}=\mathrm{Si} / \mathrm{Ni}=50$ to 15 , clear diffraction peaks of $\mathrm{NiO}$ phase appeared (Figure 3). In fact, the $\mathrm{Ni}_{50}$-HMS did not showed any XRD peaks of metal oxide. Indeed, the $\mathrm{Ni}_{15}$-HMS showed more intense reflection than $\mathrm{Ni}_{25}-\mathrm{HMS}$. This result indicated that the increase of copper content favored the formation of larger $\mathrm{NiO}$ particles extra framework.

\subsection{SEM Study}

Morphology as well as structural ordering of calcinated nickel-containing HMS samples were analyzed by electron microscopy studies. SEM pictures of $\mathrm{Ni}_{\mathrm{n}}-\mathrm{HMS}$ samples show non-uniform aggregates of small, distinct particles. Indeed, all nickel-HMS catalysts show disordered spherical structures with the presence of agglomerated particles. An example of SEM pictures of $\mathrm{Ni}_{25}-\mathrm{HMS}$ sample is shown in Figure 4.

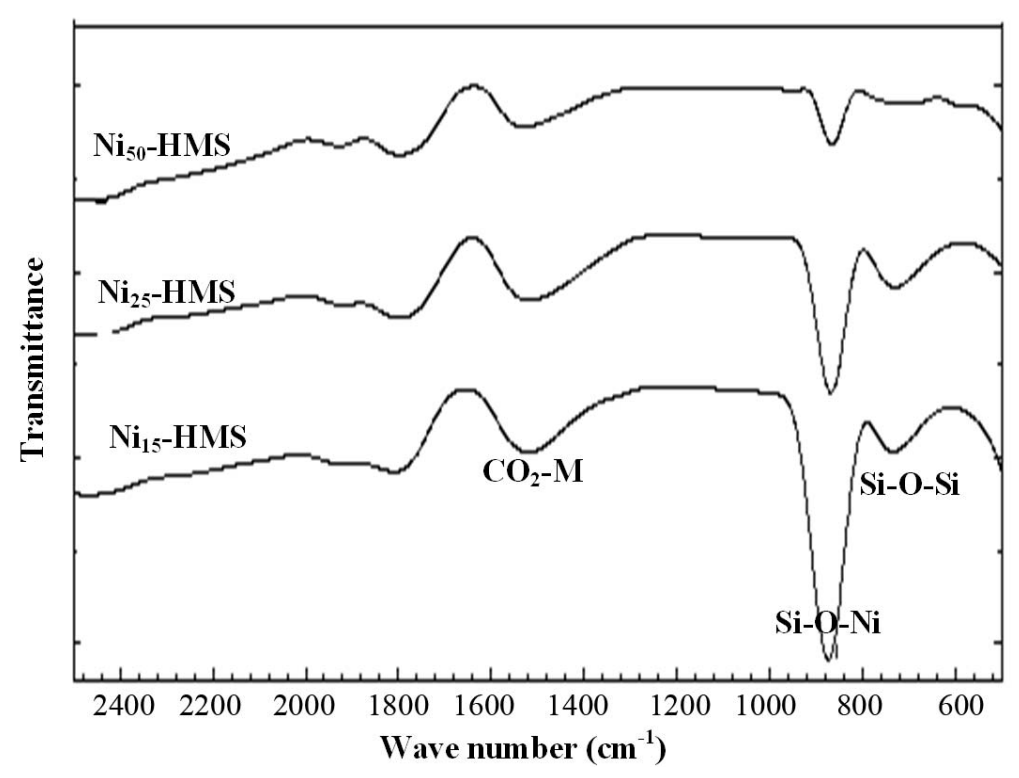

Figure 1. FT-IR spectra of Ni-HMS samples. 


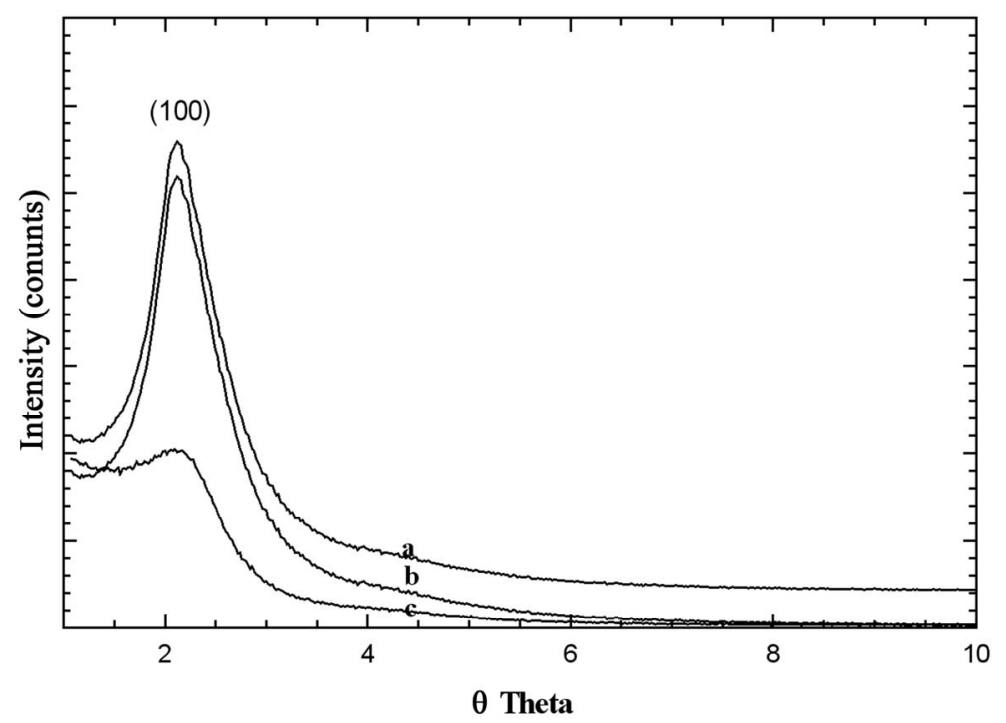

Figure 2. XRD patterns of, a: $\mathrm{Ni}_{50}-\mathrm{HMS}$; b: $\mathrm{Ni}_{25}-\mathrm{HMS}$; c: $\mathrm{Ni}_{15}-\mathrm{HMS}$ in the range of $1^{\circ}-10^{\circ}(2 \theta)$.

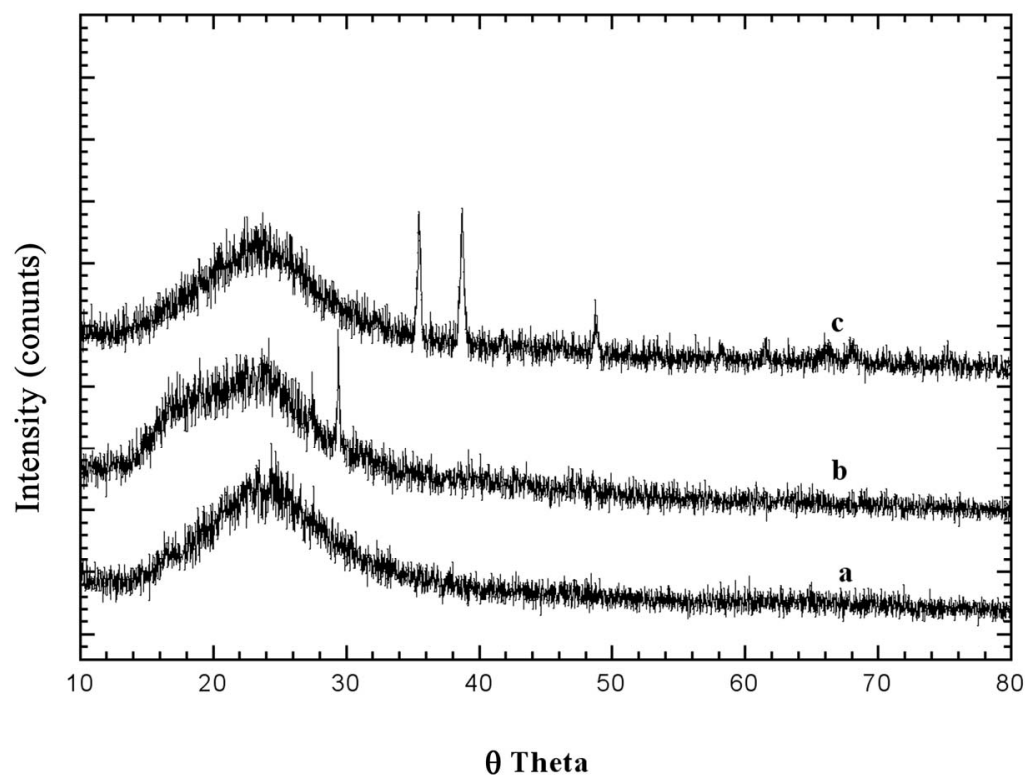

Figure 3. XRD patterns of, a: $\mathrm{Ni}_{50}-\mathrm{HMS}$; b: $\mathrm{Ni}_{25}-\mathrm{HMS}$; c: $\mathrm{Ni}_{15}-\mathrm{HMS}$ in the range of $10^{\circ}-80^{\circ}(2 \theta)$.
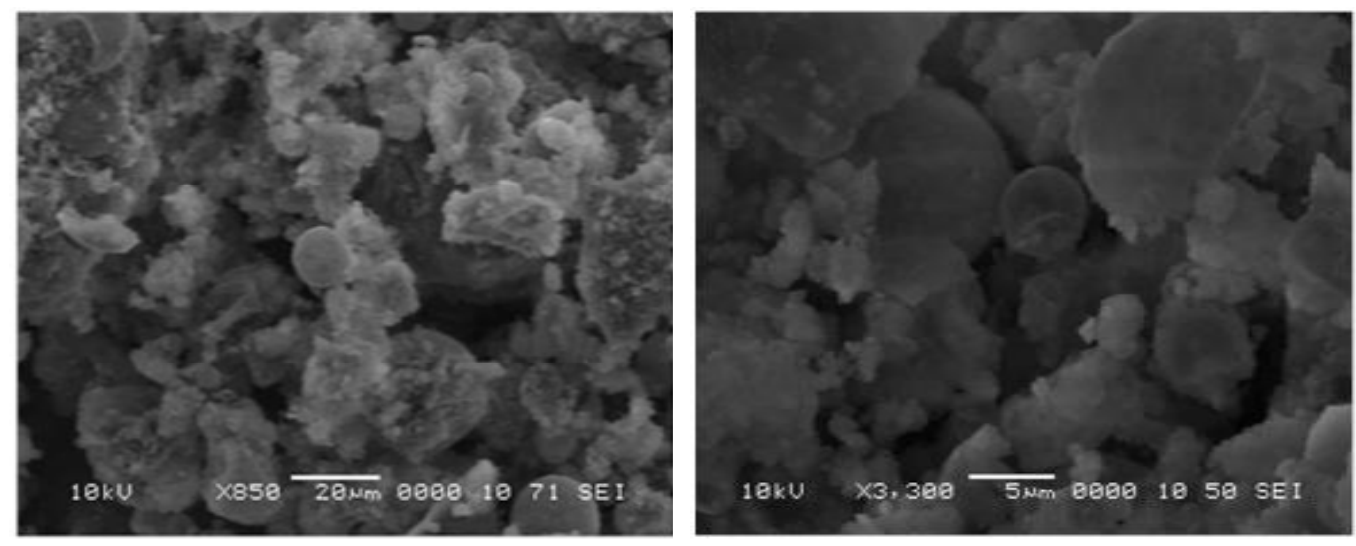

Figure 4. SEM images of calcinated $\mathrm{Ni}_{25}-\mathrm{HMS}$ sample. 


\subsection{Benzaldehyde Reduction}

The $\mathrm{Ni}_{\mathrm{n}}$-HMS catalysts exhibited initial deactivation before the steady-state was established and the degree $(2 \%$ $5 \%)$ and duration $(1-3 \mathrm{~h})$ of deactivation depended on the nickel content and reaction temperature. Figure 5 reports activity results with time on stream in the whole range of reaction temperature. In any case, the deactivation was reversible since the activity was almost totally recovered after increasing the reaction temperature. The decrease of activity is attributable to the catalyst poisoning by strongly adsorbed oxygenate molecules [32].

\subsubsection{Catalytic Activity}

The steady-state conversion increased gradually with the reaction temperature for all catalysts (Figure 6). The level and order of conversions depended on both the reaction temperature and $\mathrm{Si} / \mathrm{Ni}$ ratio. The $\mathrm{Ni}_{15}$-HMS catalyst showed high activity between $373 \mathrm{~K}$ and $513 \mathrm{~K}$ (34\% - 90\% of conversion), whereas $\mathrm{Ni}_{50}$-HMS catalyst was the less active and the order of activity was as follows: $\mathrm{Ni}_{15}-\mathrm{HMS}>\mathrm{Ni}_{25}-\mathrm{HMS}>\mathrm{Ni}_{50}-\mathrm{HMS}$.

Such an order seems to be probably related to the crystallite size of the $\mathrm{Ni}_{\mathrm{n}}$-HMS phase. Indeed, the weak activity of $\mathrm{Ni}_{50}$-HMS is probably due to the presence of small crystallites of nickel-HMS and the degree of substitution of nickel in the HMS structure. Inversely, the high degree of substitution of $\mathrm{Si}$ by $\mathrm{Ni}$ in the HMS structure encouraged the $\mathrm{NiO}$ crystallites formation on the surface of HMS structure. The presence of interaction between $\mathrm{NiO}$ phase and HMS structure contributed to the increase of the catalytic activity.

\subsubsection{Selectivity}

The fact that the aromatic nucleus is unreactive while the carbonyl substituent undergoes hydrogenation and hydrogenolysis suggests that the aromatic aldehyde reacts principally with the catalyst via the carbonyl function. It should be assumed that in the adsorbed benzaldehyde both the aromatic ring and the carbonyl group lie parallel to the active surface [14]. In such a case, the adsorbed hydrogen preferably attack the carbonyl group due to energy barriers $[14,15]$. The reaction products were: benzyl alcohol, toluene and benzene. No aromatic ring hydrogenation was observed.

\subsubsection{Benzyl Alcohol Selectivity}

In the range of reaction temperature, benzyl alcohol was formed on all catalysts (Figure 6). The reduction of the carbonyl function was observed at rather low temperature with high selectivity, regardless of the activity level (Table 2). It was produced between $393 \mathrm{~K}$ and $473 \mathrm{~K}$ on $\mathrm{Ni}_{50}$-HMS and $\mathrm{Ni}_{25}$-HMS catalysts and between 393K and $433 \mathrm{~K}$ on $\mathrm{Ni}_{15}$-HMS catalyst. The elevation of reaction temperature is not favorable to benzyl alcohol forma-
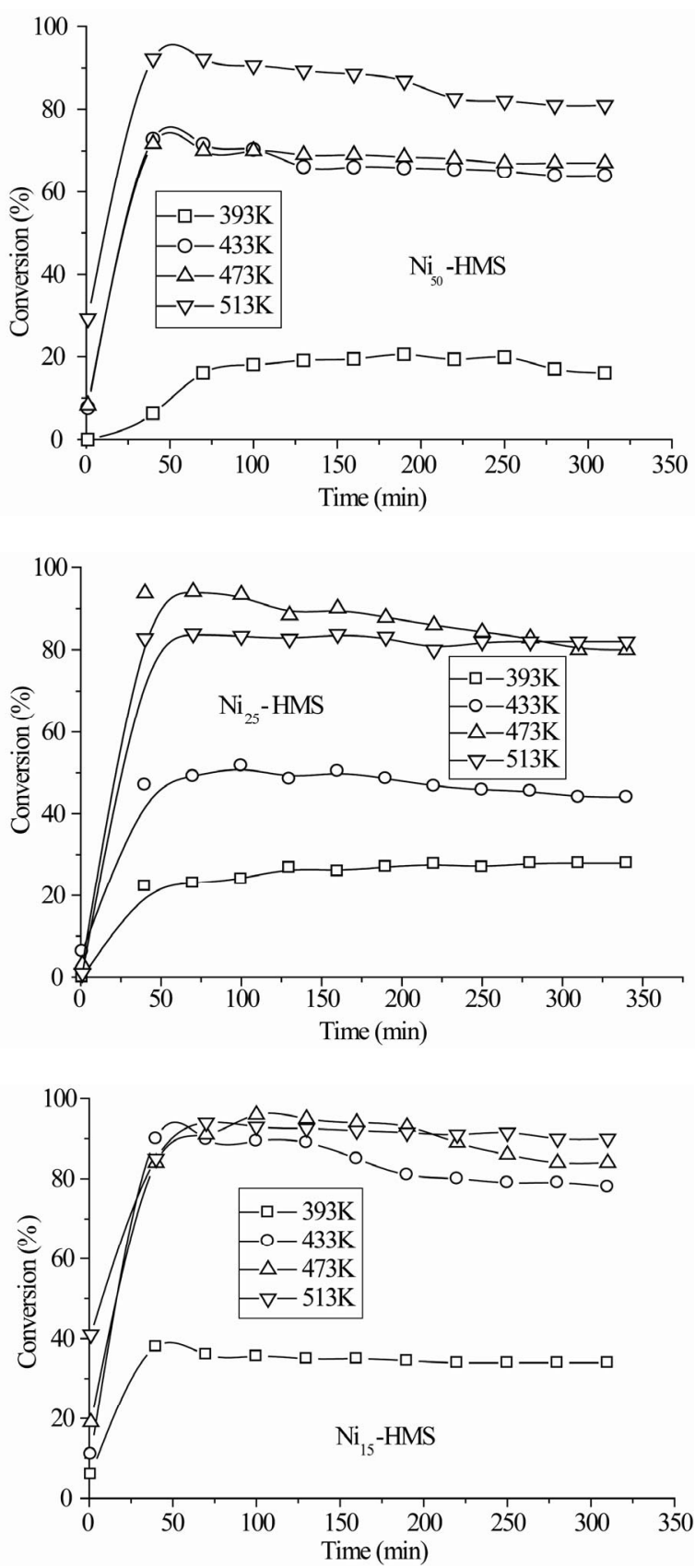

Figure 5. Conversion of benzaldehyde with time on stream in the range of reaction temperature $393 \mathrm{~K}-513 \mathrm{~K}$ under $\mathrm{H}_{2}$ flow for $\mathrm{Ni}_{\mathrm{n}}-\mathrm{HMS}$ catalysts. Pre-treatment: $\mathrm{H}_{2} / 623 \mathrm{~K}$.

tion. Indeed, the Figure 5 shows that this product decreased with increasing of reaction temperature and was totally disappeared after $473 \mathrm{~K}$ on $\mathrm{Ni}_{50}$ - $\mathrm{HMS}$ and $\mathrm{Ni}_{25^{-}}$ HMS catalysts and after $433 \mathrm{~K}$ on $\mathrm{Ni}_{15}$-HMS catalyst.

The analysis of results revealed that high selectivity to benzyl alcohol was obtained at $393 \mathrm{~K}_{\text {on }} \mathrm{Ni}_{15}$-HMS (88\% of selectivity) and it's decreased when the $\mathrm{Ni}$ content increased in order: $\mathrm{Ni}_{15}-\mathrm{HMS}(88 \%)>\mathrm{Ni}_{25}-\mathrm{HMS}(80 \%)>$ $\mathrm{Ni}_{50}$-HMS (75\%). The order of selectivity evolution is 

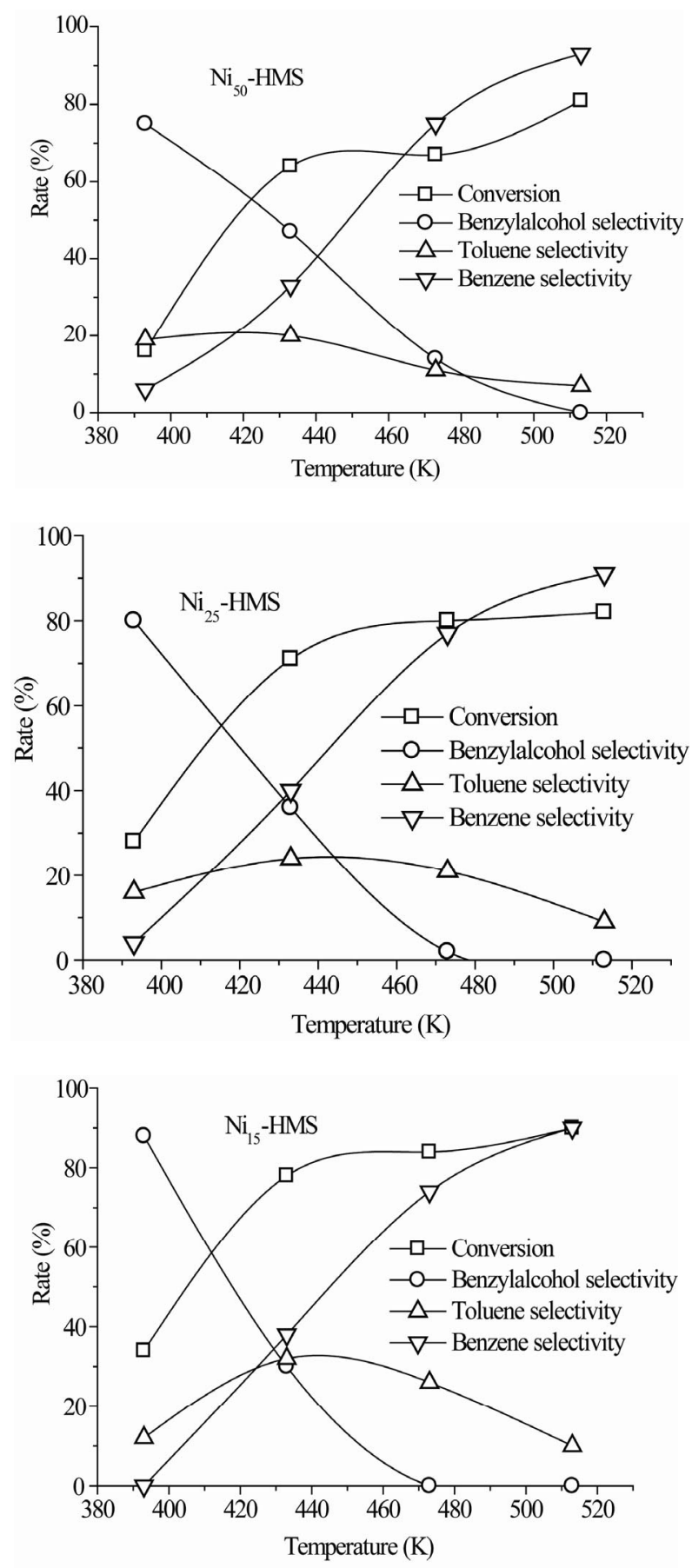

Figure 6. Steady-state conversion of benzaldehyde under $\mathrm{H}_{2}$ flow as a function of the reaction temperature. Pre-treatment: $\mathrm{H}_{2} / 623 \mathrm{~K}$.

probably due to the degree of nickel incorporation into silica frameworks.

The chemical process of benzyl alcohol formation is believed to be a 1 - 2 nucleophilic addition, with a high polarization of the transition state, as in the case of the hydrogenation of conjugated carbonyl compounds $[1,15$, 20]:

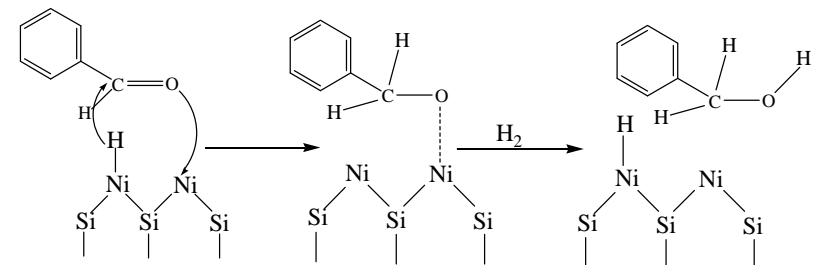

\subsubsection{Benzyl Alcohol Selectivity}

Low toluene selectivity $(<35 \%)$ was observed for all catalysts in the whole range of reaction temperature. The maximum of selectivity appeared at $433 \mathrm{~K}$ for $\mathrm{Ni}_{15}-\mathrm{HMS}$ (32\%), $\mathrm{Ni}_{25}$-HMS (24\%) and $\mathrm{Ni}_{50}$-HMS (20\%) catalysts. On the other hand, the results show that, after $433 \mathrm{~K}$, toluene selectivity decreased with elevation of temperature reaction for obtain low values at $513 \mathrm{~K}$ on all catalysts.

It is generally considered that toluene is the product of a consecutive reaction of hydrogenolysis of benzyl alcohol $[1,7,32,33]$. Indeed, flowing the nickel-HMS catalysts with the benzyl alcohol instead of benzaldehyde, selectively led to toluene production. In a parallel experiment, replacing benzaldehyde by benzyl alcohol in the reactant flow showed the formation of toluene with a selectivity of $100 \%$. However, benzyl alcohol is a complex molecule possessing several active centers such as the acidic proton and basic oxygen of the $\mathrm{O}-\mathrm{H}$ function and the reductive hydrogen of the $\mathrm{C}-\mathrm{H}$ exocyclic function. All these centers may interact with the oxide surface or dihydrogen molecule [32].

In the case of nickel-HMS catalysts, the low activity in toluene should reflect the aptitude of the surface to both adsorb the alcohol and dissociate dihydrogen. The toluene formation probably resulted in the protonation of the alcohol function on a Brönsted acid site (H-O-Si-) followed by hydrogenolysis of the protonated species on a adjacent metal site (Ni-H):

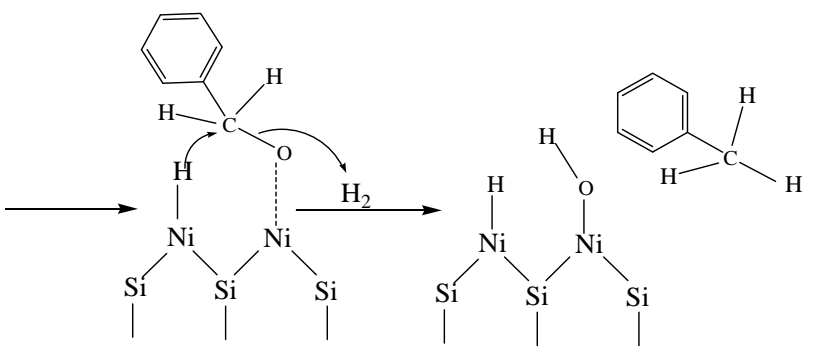

\subsubsection{Benzene Selectivity}

In the present case, benzene is formed from $313 \mathrm{~K}$ on all catalysts with very low selectivity $(<7 \%)$. In contrast to benzyl alcohol and toluene, the benzene selectivity increased with the reaction temperature and the maximum of selectivity $(90 \%-93 \%)$ was obtained at a high reaction temperature (Figure 6). High selectivity to benzene was observed for all catalysts at $513 \mathrm{~K}$ (Table 2). 
Table 2. Catalytic results for benzaldehyde hydrogenation over $\mathrm{Ni}_{\mathbf{n}}-\mathrm{HMS}$ catalysts.

\begin{tabular}{|c|c|c|c|c|c|}
\hline Catalyst & $\mathrm{T}_{\text {reaction }} \mathrm{K}$ & Conv \% & Sel $_{\text {alcohol }} \%$ & Sel $_{\text {toluene }} \%$ & Sel $l_{\text {benzene }} \%$ \\
\hline \multirow{4}{*}{$\mathrm{Ni}_{50}-\mathrm{HMS}$} & 393 & 16 & 75 & 19 & 6 \\
\hline & 433 & 64 & 47 & 20 & 33 \\
\hline & 473 & 67 & 14 & 11 & 75 \\
\hline & 513 & 81 & 0 & 7 & 93 \\
\hline \multirow{4}{*}{$\mathrm{Ni}_{25}$-HMS } & 393 & 28 & 80 & 16 & 4 \\
\hline & 433 & 71 & 36 & 24 & 40 \\
\hline & 473 & 80 & 2 & 21 & 77 \\
\hline & 513 & 82 & 0 & 9 & 91 \\
\hline \multirow{4}{*}{$\mathrm{Ni}_{15}$-HMS } & 393 & 34 & 88 & 12 & 0 \\
\hline & 433 & 78 & 30 & 32 & 38 \\
\hline & 473 & 84 & 0 & 26 & 74 \\
\hline & 513 & 90 & 0 & 10 & 90 \\
\hline
\end{tabular}

It is believed to be the product of the hydrogenolysis of the external C(aryl)-C bond of benzaldehyde [14,27]. Vannice and Poondi [6] were showed that benzene formation was produced directly from the reactant molecule and not from the alcohol or toluene intermediates. Carbon monoxide was identified as co-product of benzene [6]. On the other hand, the study of the activity as a function of time on stream showed that benzene also arose as a primary product (not presented). This result significantly shows that benzene was formed by an independent way from that of the products of benzaldehyde reduction:

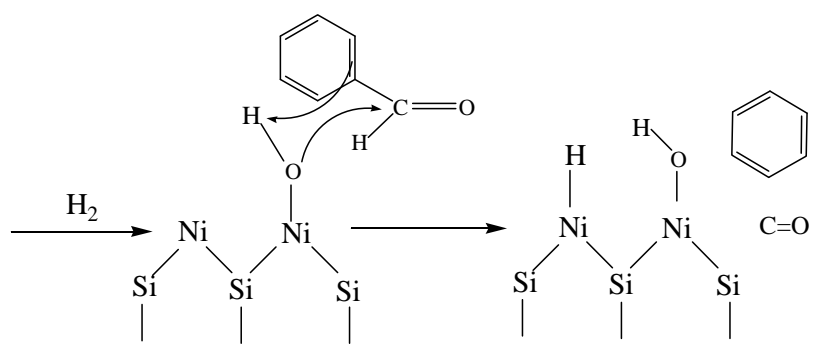

\section{Conclusion}

The hydrogenation of benzaldehyde over nickel-containing mesoporous silicas with different $\mathrm{Ni}$ contents at atmospheric pressure and $393 \mathrm{~K}-513 \mathrm{~K}$ produced competitively benzyl alcohol, toluene and with yields depending on the Si/Ni ration and the reaction temperature. The order of activity was attributed to crystallite size and degree of nickel incorporation into silica frameworks. In connection, benzyl alcohol was selectively obtained at low reaction temperature. Toluene product arose from the hydrogenolysis of benzyl alcohol on probably bifunctional sites involving metal hydride species. As to benzene, it resulted from benzaldehyde hydrogenolysis; probably through a nickel oxygenate species.

\section{REFERENCES}

[1] M. A. Vannice and R. L. Garten, “CO Hydrogenation Reactions over Titania-Supported Nickel,” Journal of Catalysis, Vol. 66, No. 1, 1980, pp. 242-247.

[2] M. Fiefelder, "Practical Catalytic Hydrogenation: Technics and Applications,” Wiley-Interscience, New York, 1971.

[3] P. N. Rylander, "Catalytic Hydrogenation in Organic Synthesis,” Academic Press, London, 1979.

[4] P. N. Rylander, "Hydrogenation Methods," Academic Press, London, 1985.

[5] K. Yoshida, C. Gonzalez-Arellano, R. Luque and P. L. Gai, "Efficient Hydrogenation of Carbonyl Compounds Using Low-Loaded Supported Copper Nanoparticles under Microwave Irradiation," Applied Catalysis A: General, Vol. 379, No. 1-2, 2010, pp. 38-44. doi:10.1016/j.apcata.2010.02.028

[6] R. Rao, A. Dandekar, R. T. K. Baker and M. A. Vannice, "Properties of Copper Chromite Catalysts in Hydrogenation Reactions," Journal of Catalysis, Vol. 171, No. 2, 1997, pp. 406-419. doi:10.1006/jcat.1997.1832

[7] D. Haffad, U. Kameswari, M. M. Bettahar, A. Chambellan and J. C. Lavalley, "Reduction of Benzaldehyde on Metal Oxides,” Journal of Catalysis, Vol. 172, No. 1, 1997, pp. 85-92. doi:10.1006/jcat.1997.1854

[8] A. Saadi, Z. Rassoul, J. Barrault and M. M. Bettahar, "Hydrogénation Sélective de la Cinnamaldéhyde en Alcool Cinnamique sur de Catalyseurs Supportés à Base de Cuivre," Journal of Algerian Chemical Society, Vol. 9, No. 2, 1999, pp. 269-276.

[9] A. Aboulayt, A. Chambellan, M. Marzin, J. Saussey, F. Maugé, J. C. Lavalley, C. Mercier and R. Jacquot, "Study of the Hydrogenation of Methyl Benzoate to Benzaldehyde on Various Metal Oxides," Studies in Surface Science and Catalysis, Vol. 78, 1993, pp. 131-138. doi:10.1016/S0167-2991(08)63312-1

[10] A. Saadi, M. M. Bettahar and Z. Rassoul, "Reduction of Benzaldehyde on Copper Supported on $\mathrm{SiO}_{2}$. Effect of 
Method of Preparation,” Studies in Surface Science and Catalysis, Vol. 130, 2000, pp. 2261-2266. doi:10.1016/S0167-2991(00)80805-8

[11] A. Saadi, R. Merabti, M. M. Bettahar and Z. Rassoul, "Catalyseurs $\mathrm{Cu} / \mathrm{MO}(\mathrm{M}=\mathrm{Mg}, \mathrm{Ca}, \mathrm{Sr})$. Caractérisation par des Réactions Tests,” Journal of Algerian Chemical Society, Vol. 11, No. 2, 2001, pp. 231-240.

[12] R. Merabti, A. Saadi, Z. Rassoul and M. M. Bettahar, "Caractérisations Physico-Chimiques des Catalyseurs à Base de Nickel Supportés,” Journal of Algerian Chemical Society, Vol. 16, No. 1, 2006, pp. 39-47.

[13] M. A. Keane, "Gas Phase Hydrogenation/Hydrogenolysis of Benzaldehyde and O-Tolualdehyde over $\mathrm{Ni} / \mathrm{SiO}_{2}$," Journal of Molecular Catalysis A: Chemical, Vol. 118, No. 2, 1997, pp. 261-269. doi:10.1016/S1381-1169(96)00386-X

[14] R. Hubaut, J. P. Bonnelle and M. Daage, "Selective Hydrogenation of Heavy Polyunsaturated Molecules on Copper-Chromium Catalysts," Journal of Molecular Catalysis, Vol. 55, No. 1, 1989, pp. 170-183. doi:10.1016/0304-5102(89)80251-2

[15] D. Poondi and M. A. Vannice, "The Influence of MSI (Metal-Support Interactions) on Phenylacetaldehyde Hydrogenation over Pt Catalysts," Journal of Molecular Catalysis A: Chemical, Vol. 124, No. 1, 1997, pp. 79-89. doi:10.1016/S1381-1169(97)00066-6

[16] M. W. De Lange, J. G. Van Ommen and L. Lefferts, "Deoxygenation of Benzoic Acid on Metal Oxides: 2. Formation of Byproducts,” Applied Catalysis A: General, Vol. 231, No. 1-2, 2002, pp. 17-26. doi:10.1016/S0926-860X(01)00702-5

[17] S. Paganelli, U. Matteoli, A. Scrivanti and C. Botteghi, "Pt0-Complexes as Catalyst Precursors for Homogeneous Carbon=Carbon and Carbon=Oxygen Double Bond Hydrogenation,” Journal of Organometallic Chemistry, Vol. 397, No. 3, 1990, pp. 375-381. doi:10.1016/0022-328X(90)85337-X

[18] J. A. Schreifels, P. C. Maybury and W. E. Swartz, “XRay Photoelectron Spectroscopy of Nickel Boride Catalysts: Correlation of Surface States with Reaction Products in the Hydrogenation of Acrylonitrile," Journal of Catalysis, Vol. 65, No. 1, 1980, pp. 195-206. doi:10.1016/0021-9517(80)90294-8

[19] A. Saadi, R. Merabti, Z. Rassoul and M. M. Bettahar, "Hydrogenation of Benzaldehyde over Supported Nickel Catalysts," Journal of Molecular Catalysis A: Chemical, Vol. 253, No. 1-2, 2006, pp. 79-85. doi:10.1016/j.molcata.2006.03.003

[20] M. A. Vannice, "Hydrogenation of co and Carbonyl Functional Groups,” Catalysis Today, Vol. 12, No. 2-3, 1992, pp. 255-267.

[21] C. T. Kresge, M. E. Leonowicz, W. J. Roth and J. C. Beck, "Ordered Mesoporous Molecular Sieves Synthesized by a Liquid-Crystal Template Mechanism,” Nature, Vol. 359, No. 6397, 1992, pp. 710-712. http://134.243.5.70/ASSETS/87CB6FBC90C84546BA13 660DB519F346/200207j5.pdf

[22] J. S. Beck, J. C. Vartuli, W. J. Roth, M. E. Leonowicz, C.
T. Kresge, K. D. Schmitt, C. T. W. Chu, D. H. Olson, E. W. Sheppard, S. B. McCullen, J. B. Higgins and J. L. Schlenker, "A New Family of Mesoporous Molecular Sieves Prepared with Liquid Crystal Templates,” Journal of American Chemical Society, Vol. 114, No. 27, 1992, pp. 10834-10843. doi:10.1021/ja00053a020

[23] P. T. Tanev, M. Chibwe and T. J. Pinnavaia, "Titanium-Containing Mesoporous Molecular Sieves for Catalytic Oxidation of Aromatic Compounds,” Nature, Vol. 368, 1994, pp. 321-323. doi:10.1038/368321a0

[24] A. Yin, J. Qu, X. Guo, W. L. Dai and K. Fan, "The Influence of B-Doping on the Catalytic Performance of $\mathrm{Cu} / \mathrm{HMS}$ Catalyst for the Hydrogenation of Dimethyloxalate," Applied Catalysis A: General, Vol. 400 No. 1-2, 2011, pp. 39-47. doi:10.1016/j.apcata.2011.04.011

[25] A. Sayari, "Catalysis by Crystalline Mesoporous Molecular Sieves,” Chemistry of Materials, Vol. 8, No. 8, 1996, pp. 1840-1852. doi:10.1021/cm950585+

[26] A. Yin, C. Wen, X. Guo, W. L. Dai and K. Fan, "Influence of Ni Species on the Structural Evolution of $\mathrm{Cu} / \mathrm{SiO}_{2}$ Catalyst for the Chemoselective Hydrogenation of $\mathrm{Di}$ methyl Oxalate,” Journal of Catalysis, Vol. 280, No. 1, 2011, pp. 77-88. doi:10.1016/j.jcat.2011.03.006

[27] C. Y. Ma, J. Cheng, H. L. Wang, Q. Hu, H. Tian, C. He and Z. P. Hao, "Characteristics of Au/HMS Catalysts for Selective Oxidation of Benzyl Alcohol to Benzaldehyde," Catalysis Today, Vol. 158, No. 3-4, 2010, pp. 246-251. doi:10.1016/j.cattod.2010.03.080

[28] E. S. Vasiliadou and A. A. Lemonidou, "Investigating the Performance and Deactivation Behaviour of Silica-Supported Copper Catalysts in Glycerol Hydrogenolysis," Applied Catalysis A: General, Vol. 396, No. 1-2, 2011, pp. 177-185. doi:10.1016/j.apcata.2011.02.014

[29] A. Tuel, I. Arcon and J. M. M. Millet, "Investigation of Structural Iron Species in Fe-Mesoporous Silicas by Spectroscopic Techniques," Journal of the Chemical Society, Faraday Transactions, Vol. 94, No. 23, 1998, pp. 3501-3510. doi:10.1039/A806912C

[30] X. Lu and Y. Yuan, "Copper-Containing Hexagonal Mesoporous Silicas for Styrene Epoxidation Using Tert-Butylhydroperoxide," Applied Catalysis A: General, Vol. 365, No. 2, 2009, pp. 180-186. doi:10.1016/j.apcata.2009.06.012

[31] K. Bachari, A. Touileb, N. Tahir, A. Saadi, D. Halliche and O. Cherifi, "Catalytic Propeties of Cr-HMS Materials in the Benzylation of Benzene with Benzylchloride,” $\mathrm{Ki}$ netics and Catalysis, Vol. 52, No. 1, 2011, pp. 48-54. doi:10.1134/S0023-158411010022

[32] A. Saadi, Z. Rassoul and M. M. Bettahar, "Gas Phase Hydrogenation of Benzaldehyde over Supported Copper Catalysts," Journal of Molecular Catalysis A: Chemical, Vol. 164, No. 1-2, 2000, pp. 205-216. doi:10.1016/S1381-1169(00)00199-0

[33] R. Merabti, K. Bachari, D. Halliche, Z. Rassoul and A. Saadi, "Synthesis and Characterization of Activated Copper or Nickel and Their Catalytic Behavior towards Benzaldehyde Hydrogenation," Reaction Kinetics, Mechanisms and Catalysis, Vol. 101, 2010, pp. 195-208.

doi:10.1007/S11144-0100215-X 